\title{
Qualidade pós-colheita do tomate de mesa convencional e orgânico
}

\author{
Postharvest quality of conventional and organic tomatoes
}

\author{
Sila Mary Rodrigues FERREIRA ${ }^{1 \star}$, Diomar Augusto de QUADROS², Elisa Noemberg Lazzari KARKLE \\ Jair José de LIMA ${ }^{1}$, Lindamir Tomczak TULLIO ${ }^{1}$, Renato João Sossela de FREITAS ${ }^{4}$
}

\section{Resumo}

O presente trabalho teve como objetivo avaliar a qualidade pós-colheita de frutos de tomate de mesa de diferentes sistemas de cultivos. As amostras de tomate convencional, cv. Raísa (LV), e orgânico, cv. Santa Clara, foram mantidas a uma temperatura de $23,5 \pm 2{ }^{\circ} \mathrm{C}$, com UR de $74 \% \pm 5$ e submetidas a análise da massa, peso específico, cinzas, sólidos totais, sólidos solúveis totais, acidez titulável total, relação sólidos solúveis totais/acidez titulável total, $\mathrm{pH}$, vitamina C, Salmonella spp., coliformes totais, coliformes fecais, bolores e leveduras e análise sensorial, que foi realizada pela Análise Descritiva Quantitativa - ADQ. O tempo de armazenagem foi de 13 e 14 dias para o tomate de mesa cultivado nos sistemas convencional e orgânico, respectivamente. O tempo de armazenagem foi de 13 e 14 dias para o tomate de mesa cultivado nos sistemas convencional e orgânico, respectivamente. A perda de massa foi significativamente inferior (3,74\%) no tomate convencional. Ambas as amostras apresentaram similar comportamento na análise física, química sensorial e microbiológica nos estádios de maturação.

Palavras-chave: tomate de mesa; qualidade pós-colheita; alimento agroecológico; alimento orgânico.

\begin{abstract}
The objective of this work was to evaluate the postharvest quality of fruits grown using different systems. Conventional (CS) tomatoes of the variety Raisa and Organic (OS), variety Santa Clara rustic, were stored at $23.5 \pm 2{ }^{\circ} \mathrm{C}, \mathrm{RH} 74 \% \pm 5$ and analyzed for mass, specific weight, ash, total solids, total soluble solids, total titrable acidity, total soluble solids/total titrable acidity ratio, $\mathrm{pH}$, vitamin $\mathrm{C}$, Salmonella spp., total coliforms, faecal coliforms, molds and yeasts, and sensory analysis (using Quantitative Descriptive Analyses - QDA). The time of storage was of 13 days for the conventional tomatoes and 14 days for the organic tomatoes. Weight loss $(3,74 \%)$ was lower for the conventional tomatoes. Both fruits were similar in the physical, chemical, sensory and microbiological analysis in the different maturity stages.

Keywords: tomatoes; postharvest quality; agroecological foods; organic foods.
\end{abstract}

\section{Introdução}

O tomate é uma das olerícolas mais difundidas no mundo. Além de ser uma importante commodity mundial, ocupa lugar de destaque na mesa do consumidor (BORGUINI, 2006). As perspectivas para a evolução da cultura são promissoras, tendo em vista o potencial de mercado do tomate orgânico e convencional tanto da forma in natura como industrializada.

O aumento da demanda de alimentos orgânicos que são produzidos de forma a valorizar a diversidade biológica e livre de agressões ao meio ambiente é uma tendência que favorece a criação de novas oportunidades, como emprego e renda aos produtores da agricultura familiar.

Ainda que a produtividade do sistema orgânico seja inferior e nem sempre atenda ao modelo de maximização lucrativa, busca a oferta de produtos de melhor qualidade ao consumidor. Evidências da mudança de hábito alimentar entre brasileiros sinalizam para uma maior demanda por produtos orgânicos (BORGUINI, 2002). Os consumidores diminuem suas exigências quanto ao atributo aparência externa, quando se conscientizam da importância dos alimentos orgânicos (BORGUINI; OETTERER; SILVA, 2003). Existe uma crença de que o sabor do tomate produzido pelo sistema orgânico é mais agradável em razão da maior doçura; fato afirmado pelos consumidores e produtores, que lhe atribuem a razão da maior procura (BORGUINI, 2002). Relatos de Borguini, Oetterer e Silva (2003) mostraram o maior teor de açúcar, o que de certa maneira, justifica o melhor sabor do produto orgânico que provém do grau de crescimento e maturidade fisiológica da colheita.

Por ser o tomate um fruto perecível, o armazenamento adequado retarda o amadurecimento, mantém a qualidade e prolonga a conservação (BRACKMANN et al., 2007). Desta forma, o entendimento dos processos de maturação do tomate de mesa e as características de qualidade dos frutos na armazenagem são fundamentais para a comercialização. A

Recebido para publicação em 16/7/2008

Aceito para publicação em 25/9/2009 (003437)

${ }^{1}$ Departamento de Nutrição, Universidade Federal do Paraná - UFPR, CEP 80210-170, Curitiba - PR, Brasil, E-mail: sila@ufpr.br

2 Universidade Federal do Paraná - UFPR, Campus Litoral, CEP 83260-000, Matinhos - PR, Brasil

3 PhD em Grain Science and Industry, Kansas State University, 66045, Kansas City - Kansas, EUA

${ }^{4}$ Programa de Pós-graduação em Tecnologia de Alimentos, Universidade Federal do Paraná - UFPR, CEP 81531-990, Curitiba - PR, Brasil

${ }^{*}$ A quem a correspondência deve ser enviada 
cor é o atributo de qualidade mais atrativo que, por sua vez, está relacionada à aparência, teor de açúcares, acidez, pH, textura, sabor e suculência. O estádio de maturação do tomate influencia na vida pós-colheita, no amadurecimento e auxilia a escolha do consumidor, juntamente com o tamanho, forma e defeitos externos do fruto. No supermercado, somente aqueles produtos que correspondem às expectativas do consumidor são comercializados.

As características de qualidade (BHOWMIK; PAN, 1992; FERREIRA et al., 2006; MARTÍNEZ-ROMERO et al., 2009) do tomate cultivado no sistema convencional foram investigadas em diferentes temperaturas, tempos, embalagens (KLUGE; MINAMI, 1997; CHIUMARELLI; FERREIRA, 2006; CLIFF et al., 2009) e estádios de maturação (ZAMBRANO; MOYEJA; PACHECO, 1996). No tomate orgânico, ainda que tenham sido estudadas algumas características químicas, nutricionais e sensoriais (BOURN; PRESCOTT, 2002; AGENCE..., 2003; BORGUINI, 2002, 2006; CARIS-VEYRAT, 2004) inexistem relatos sobre a qualidade pós-colheita, principalmente em cultivares nacionais.

Mesmo sendo o tomate orgânico um potencial de mercado e uma alternativa econômica para os produtores familiares, ainda existe carência de informação científica em relação a sua conservação. Em razão do exposto, o presente trabalho teve como objetivo determinar a qualidade pós-colheita do tomate de mesa (Lycopersicon esculentum Mill.) cultivado nos sistemas convencional e orgânico.

\section{Material e métodos}

\subsection{Matéria-prima}

Foram colhidos tomates de mesa, subclasse média no estádio de maturação verde maduro em propriedades próximas e sob condições edafoclimáticas semelhantes de $28 \pm 2{ }^{\circ} \mathrm{C}$ no Município de Colombo - PR. No Sistema Convencional (SC), foi utilizada a cv. Raísa (Longa Vida - LV), plurilocular do grupo redondo, e no Sistema Orgânico (SO) foi empregada a cv. Santa Clara rústica, bilocular do grupo oblongo (Tabela 1). No local foram submetidos à higienização habitual, acondicionados em caixas tipo $k$ de madeira empregadas no transporte comercial do tomate e transportados ao laboratório de Tecnologia de Alimentos do Departamento de Nutrição da UFPR.

Tabela 1. Estádios de maturação versus tempo de armazenamento do tomate de mesa cultivado nos sistemas convencional e orgânico.

\begin{tabular}{ccl}
\hline Dia & Sistema convencional & Sistema orgânico \\
\hline 0 & Verde maduro & Verde maduro \\
2 & Pintado & Pintado \\
5 & Rosado & Rosado \\
7 & Vermelho & Vermelho \\
8 & & Vermelho maduro \\
10 & Vermelho maduro & \\
14 & Passado & \\
15 & & Passado \\
\hline
\end{tabular}

\subsection{Condições de armazenamento}

O esquema fatorial foram 2 tratamentos $\times 3$ repetições $\times 6$ estádios de maturação para as análises químicas, bolores e leveduras. Somente dois estádios de maturação pra análise física e a sensorial. As parcelas foram constituídas de 60 frutos. No dia zero do ensaio, foram retirados aleatoriamente os tomates para a análise química e para a análise microbiológica. A parcela da análise física foi constituída de 13 frutos, em triplicata. Os frutos foram armazenados em sala ventilada de aproximadamente $24 \mathrm{~m}^{2}$ e mantidos sem controle automático da temperatura de $23,5 \pm 2{ }^{\circ} \mathrm{C}$, com UR de $74 \% \pm 5$. Para análises, foram subtraídos os tomates quando no mínimo $80 \%$ dos frutos atingiram os estádios de maturação: pintado, rosado, vermelho e vermelho maduro. A partir do estádio de maturação vermelho foram retirados aleatoriamente 20 frutos para a análise sensorial. $\mathrm{O}$ experimento foi encerrado quando os frutos atingiram o estádio passado, ou seja, os frutos estavam amolecidos e de cor vermelha púrpura.

\subsection{Análise física e química}

A análise física, verificada no primeiro e no último dia, envolveu a determinação de massa, volume, volume específico e peso específico dos frutos (FERREIRA, 2004). Para a análise química, os frutos foram picados, homogeneizados, acondicionados em embalagem de poliestireno e, depois de identificadas, foram congeladas ou conduzidas para as análises. As amostras para análise foram armazenadas em refrigerador a $7 \pm 2{ }^{\circ} \mathrm{C}$. Para análise da acidez titulável total, ácido cítrico, $\mathrm{pH}$ (INSTITUTO..., 2008), cinzas, vitamina C (ASSOCIATION..., 2000), as amostras foram utilizadas resfriadas e para os sólidos solúveis totais (INSTITUTO..., 2008) e acúçares (NELSON, 1944) foram congeladas a $-18^{\circ} \mathrm{C}$. A relação dos Sólidos Solúveis Totais (SST) e a Acidez Titulável Total (ATT) foi expressa em ${ }^{\circ} \mathrm{Brix} / \mathrm{mg} \%$ (INSTITUTO..., 2008). A acidez, expressa em g de ácido cítrico foi calculada considerado-se o equivalente-grama (INSTITUTO..., 2008). Os resultados da análise física foram submetidos ao teste $T$-student, em nível de $5 \%$ de probabilidade de erro.

\subsection{Análise sensorial}

Os frutos, após a higienização em água corrente, imersão em solução de hipoclorito a 2,5\% por 15 minutos e secos, foram agrupados em parcelas de 10 unidades e acondicionados em embalagens de polietileno que foram etiquetadas, identificadas, fechadas e conservadas em refrigeração a $7 \pm 2{ }^{\circ} \mathrm{C}$ no prazo máximo de 20 horas. Antes da análise sensorial, as amostras foram mantidas em temperatura ambiente, por no mínimo uma hora, até a avaliação pelos 10 julgadores. A análise sensorial seguiu a metodologia, ficha de avaliação, atributos e instrumento dos termos descritivos definidos por Ferreira (2004). Foram entregues aos julgadores, em primeiro lugar, os tomates inteiros para análise dos descritores: cor, defeitos na superfície, firmeza ao toque e aparência geral externa. As amostras, depois de fatiadas em rodelas de $0,5 \mathrm{~cm}$ a partir do pedúnculo, foram avaliadas segundo os demais descritores. 


\subsection{Análise microbiológica}

A qualidade microbiológica do tomate foi avaliada por meio da análise de Salmonella spp., coliformes fecais, coliformes totais e bolores e leveduras (AMERICAN..., 1992). No primeiro dia de ensaio foram efetuadas todas as análises. Quando a amostra atingiu o estádio de maturação respectivo, foi realizada a análise de bolores e leveduras. Os padrões e critérios para análise dos resultados para Salmonella spp. (ausente em $25 \mathrm{~g}$ ) e coliformes fecais $\left(10^{2}\right.$ UFC. $\left.\mathrm{g}^{-1}\right)$ seguiram a legislação para hortaliças (BRASIL, 2001), já que não existe padrão para tomate de mesa. Para coliformes totais (UFC. ${ }^{-1}$ ), foi adotada a contagem $<10^{2}$ recomendada por Reis et al. (2003) e, para bolores e leveduras, a contagem de $<10^{4}$, um vez que a contagem acima pode ser perigosa em razão da possível formação de micotoxinas.

\section{Resultados e discussão}

\subsection{Tempo de armazenagem}

O tempo de armazenamento dos frutos da cv. Raísa do sistema convencional e cv. Santa Clara do sistema orgânico (Tabela 1) indicou que o ponto ideal de comercialização foi de até 13 dias para o tomate convencional e de 14 dias para o tomate orgânico. Os valores foram compatíveis aos encontrados por Kluge e Minami (1997) e Chiumarelli e Ferreira (2006) e inferiores ao de Zambrano, Moyeja e Pacheco (1996) e Sanino, Cortez e Medero (2003). As diferenças podem ser atribuídas às condições do ensaio, estádio de maturação inicial e final dos frutos, genótipo da cultivar, sistema de manejo pós-colheita, condições de armazenamento, temperatura e umidade relativa (KLUGE; MINAMI, 1997; SANINO; CORTEZ; MEDERO, 2003). Esperava-se que a cv. Raísa longa vida apresentasse superior tempo de armazenagem, pois frutos mutantes, gene rin, quando submetidos ao armazenamento apresentam maior firmeza, resultante da solubilização das substâncias pécticas da parede celular, pela ação das enzimas Poligalacturonase (PG) e Pectinametilesterase (PME) (VILAS BOAS et al., 2000; FACHIN, 2003). O tomate de mesa, independente do sistema de cultivo, atingiu o estádio de maturação pintado em dois dias, ratificando Wien (1997). O tempo de 14 dias para o tomate orgânico reflete no aspecto econômico tanto para o comerciante como para o consumidor.

\subsection{Análise física e química}

$\mathrm{Na}$ análise física (Tabela 2), a perda de massa do tomate convencional foi de $3,74 \%$ enquanto que a do orgânico foi de $7,74 \%$. No tomate convencional, o valor foi semelhante aos encontrados na literatura (KLUGE; MINAMI, 1997; WILLS; KU, 2002; CHIUMARELLI; FERREIRA et al., 2006; FERREIRA et al., 2008), porém superior a Martínez-Romero et al. (2009) e Cliff et al. (2009). A diferença da perda de massa em relação aos autores pode ser resultante do genótipo do fruto, temperatura, umidade relativa do ar, tempo de armazenamento (BHOWMIK; PAN, 1992; KLUGE; MINAMI, 1997), e à atividade da PG, que aumenta a permeabilidade da parede celular aumentando a transpiração (FACHIN, 2003). O tomate convencional seguiu a tendência de, durante o tempo de armazenamento, apresentar
Tabela 2. Análise física do tomate de mesa cultivado nos sistemas convencional e orgânico nos estádios de maturação vermelho e vermelho maduro.

\begin{tabular}{lcccc}
\hline \multicolumn{1}{c}{ Atributos } & CVE & CVM & OVE & OVM \\
\hline Massa $(\mathrm{g})$ & $108,5^{\mathrm{a}}$ & $104,44^{\mathrm{b}}$ & $88,19^{\mathrm{c}}$ & $81,36^{\mathrm{d}}$ \\
Perda de massa (\%) & - & 3,74 & - & 7,74 \\
Volume $\left(\mathrm{cm}^{3}\right)$ & $114,68^{\mathrm{a}}$ & $109,26^{\mathrm{b}}$ & $96,51^{\mathrm{c}}$ & $86,75^{\mathrm{d}}$ \\
Peso específico $\left(\mathrm{g} / \mathrm{cm}^{3}\right)$ & $0,946^{\mathrm{a}}$ & $0,957^{\mathrm{ad}}$ & $0,917^{\mathrm{c}}$ & $0,941^{\mathrm{d}}$ \\
\hline \multicolumn{4}{l}{ Médias seguidas pela mesma letra minúscula não diferem significativamente pelo teste } \\
$T$ - student de duas médias ao nível de 5\% no programa Excel. Sistema convencional: \\
CVE - convencional verde maduro, CVM - Convencional Vermelho Maduro; sistema \\
orgânico: OVE - orgânico verde maduro, OVM - vermelho maduro.
\end{tabular}

maior peso específico em relação à amostra orgânica que pode ser justificada pela maior quantidade de sólidos totais presente na amostra conforme mostra a Figura 1.

Os resultados da análise química (Figura 1) mostraram similar comportamento das amostras nas diferentes variáveis estudadas. A quantidade de cinzas que variou de 0,24 a $0,37 \%$ indicou a concentração de minerais nas amostras. A tendência do tomate orgânico em apresentar maior teor de cinzas foi compatível a Borguini (2002) e contrário aos trabalhos relatados por Afssa (AGENCE..., 2003), quando compararam amostras de tomates de diferentes sistemas.

A quantidade de Sólidos Solúveis Totais (SST), açúcares redutores e sólidos totais dos frutos foi próxima aos valores mencionados na literatura (ZAMBRANO; MOYEJA; PACHECO, 1996; KLUGE; MINAMI, 1997; WILLS; KU, 2002). Um dos fatores que favoreceram a elevação dos SST do tomate convencional foi a perda de massa, a qual concentrou os teores de açúcares no interior dos tecidos (ZAMBRANO; MOYEJA; PACHECO, 1996; KLUGE; MINAMI, 1997), como também as reações de amadurecimento que provocam a quebra do amido para açúcares simples. O comportamento dos SST do tomate orgânico pode ser justificado em razão da redução dos açúcares redutores e sólidos totais (Figura 1) durante o armazenamento, que contrabalançou a perda de massa. $\mathrm{O}$ aumento de açúcares redutores de 2,27 a 2,72, porém menor que o registrado por Zambrano, Moyeja e Pacheco (1996) durante a maturação do tomate convencional, se deve à degradação de amido e acúmulo de monossacarídeos, frutose e glicose (ZAMBRANO; MOYEJA; PACHECO, 1996). Os sólidos totais que variaram de 4,4 a 6,0\% em ambas as cultivares são compatíveis a Zambrano, Moyeja e Pacheco (1996) e Wien (1997) para tomate vermelho.

A acidez titulável na amostra convencional se manteve constante, em torno de $0,21 \%$, durante o período do armazenamento, enquanto a amostra orgânica apresentou $0,20 \%$, com leve declínio nos estágios vermelho e vermelho maduro decorrente do processo respiratório ou da conversão dos ácidos orgânicos em açúcares (BHOWMIK; PAN, 1992). Zambrano, Moyeja e Pacheco (1996) observaram um aumento da acidez titulável nos estádios pintado, amarelo rosado e rosado, com redução no estádio vermelho e declínio nos estádios subsequentes. Wills e Ku (2002) encontraram redução da acidez titulável a partir do estádio pintado e 10 dias de estoque. 

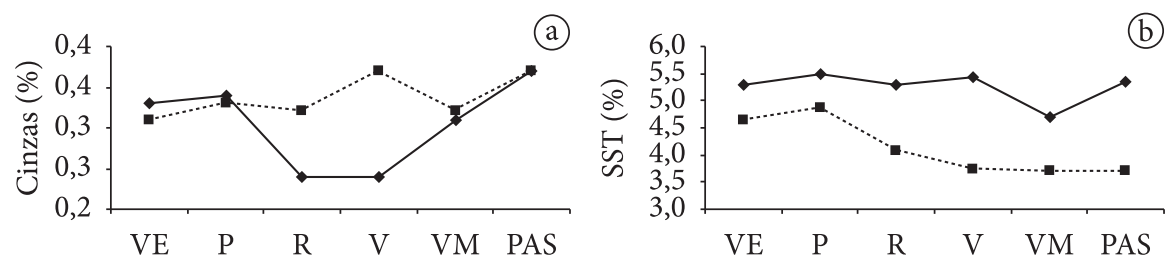

(b)
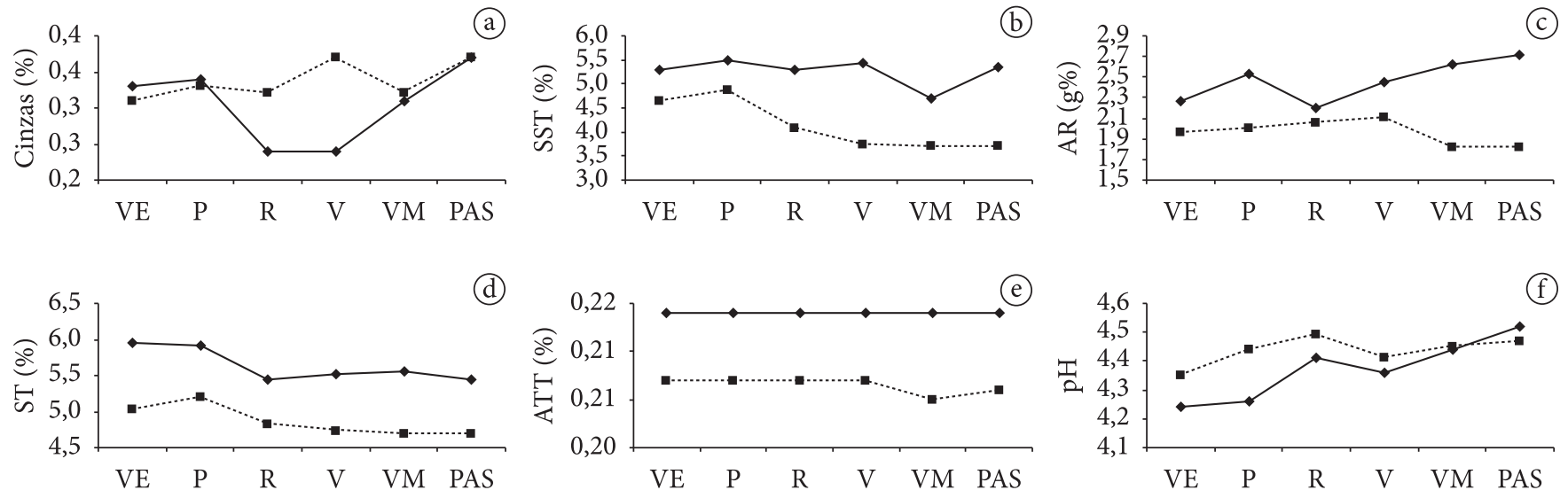

(g)

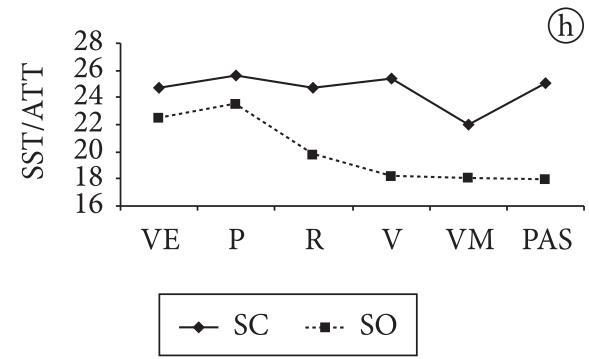

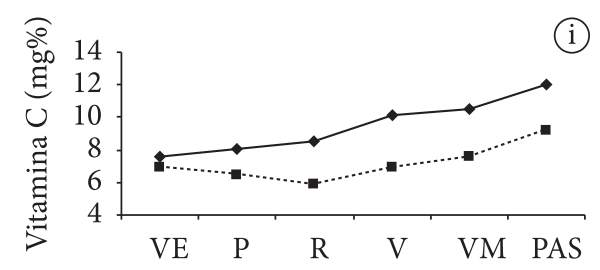

(i)

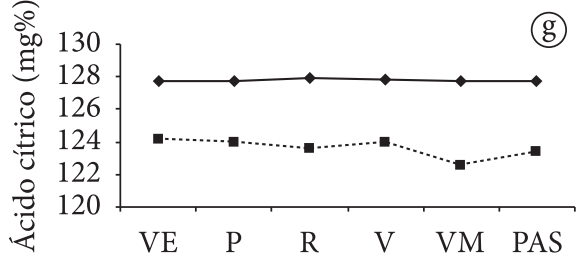

Figura 1. Composição química dos diferentes estádios de maturação do tomate de mesa cultivados nos sistemas convencional e orgânico. a) teor de cinzas; b) sólidos solúveis; c) açúcares redutores; d) sólidos totais; e) acidez titulável; f) pH; g) ácido cítrico; h) relação SST/ATT; e i) vitamina C. Sistema de cultivo: SC - Convencional; SO - Orgânico. Estádios de maturação: VE - verde maduro; P - Pintado; R - Rosado; V - Vermelho; VM - Vermelho Maduro; PAS - Passado.

$\mathrm{O}$ pH que variou de 4,24 até 4,52 ficou próximo a 4,28 registrado por Cliff et al. (2009). As curvas do $\mathrm{pH}$ foram similares para ambas as cultivares, porém com tendência à menor acidez a amostra orgânica. Este resultado confirmou Rêgo, Finger e Casali (1999) que observaram uma redução de $3 \%$ no $\mathrm{pH}$ em frutos mutantes cv. Santa Clara.

A quantidade de ácido cítrico foi superior e constante no tomate de mesa convencional, enquanto na amostra orgânica a acidez diminuiu a partir do estádio vermelho, confirmando tomates de menor acidez. Em frutos cítricos, a acidez do suco varia proporcionalmente com o conteúdo de vitamina C. Essa variação embora direta não é linear, o que indica a presença de outros ácidos. Os valores superiores encontrados por Borguini (2002) podem ser atribuídos à diferença genética, solo, manejo e temperatura média local.

A relação SST/ATT, que variou de 24,77 a 21,96 no sistema convencional e de 25,46 a 18,05 no sistema orgânico, indica uma excelente combinação de açúcar e ácido que se correlacionam com sabor suave dos frutos (ZAMBRANO; MOYEJA; PACHECO, 1996). Para Kader et al. (1978), frutos de alta qualidade contêm mais de $0,32 \%$ de acidez titulável, $3 \%$ de SST e relação SST/ATT maior que 10. Wills e Ku (2002) encontraram uma relação de SST/ATT de 3,2 e 3,8.

A quantidade de vitamina $C$ que variou de 5,9 a $11,9 \%$ foi inferior ao registrado na literatura (BORGUINI, 2002; CARISVEYRAT et al., 2004; MARTINEZ-ROMERO et al., 2009).
Similar ao comportamento observado por Zambrano, Moyeja e Pacheco (1996), o teor de vitamina C de ambas as cultivares apresentou aumento constante nos diferentes estádios de maturação. Segundo Hobson e Davies (1971 apud ZAMBRANO; MOYEJA; PACHECO, 1996), o aumento gradativo do teor de vitamina $\mathrm{C}$ durante o amadurecimento do tomate é reflexo da translocação contínua e síntese do ácido L-ascórbico proveniente do acúmulo de sólidos solúveis e açúcares redutores entre o estádio pintado e vermelho maduro.

Os valores aferidos na $\mathrm{ADQ}$ aos tomates convencional e orgânico nos diferentes estádios de maturação estão na Figura 2. A cor da superfície do tomate convencional e orgânico no estádio vermelho recebeu dos provadores valores de $6,8 \mathrm{e}$ 5,8 , respectivamente, e no estádio vermelho maduro recebeu nota 7,1. A evolução da coloração dos frutos de vermelho para vermelho maduro, que foi também observada por Batu (2004), se deve à degradação de clorofila por clorofilases (WIEN, 1997).

Os defeitos de superfície $(1,9$ e 2,2) dos estádios vermelho e vermelho maduro do tomate orgânico, respectivamente aumentaram à medida que se desenvolvia a maturação. $\mathrm{Na}$ amostra convencional, ocorreu o inverso $(2,4$ e 1,9$)$. $O$ fato pode ser atribuído aos sintomas externos de amadurecimento irregular que incluem estrias verdes, brancas ou rosas, ou ainda manchas na superfície que podem desaparecer quando o fruto está completamente maduro. 




$$
\cdots \mathrm{CV} \leadsto \mathrm{OV}
$$

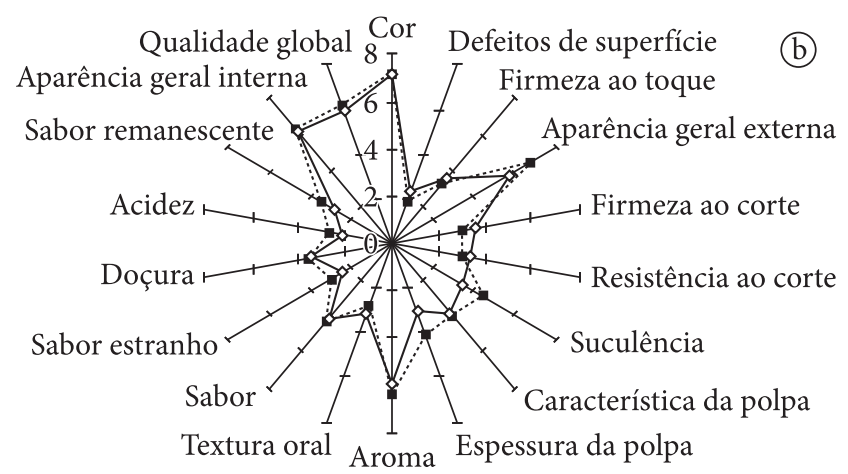

$\cdots \mathrm{CVM} \nrightarrow \mathrm{OVM}$

Figura 2. Perfil sensorial dos estádios vermelho e vermelho maduro do tomate de mesa cultivado nos sistemas convencional e orgânico. a) estádio vermelho; b) estádio vermelho maduro; CV - sistema Convencional Vermelho; OV - sistema Orgânico Vermelho; CVM - sistema Convencional Vermelho Maduro; OVM - sistema Orgânico Vermelho Maduro.

Os tomates no estádio vermelho foram identificados como mais firmes enquanto que os do estádio vermelho maduro, mais moles, sendo compatíveis com Batu (2004) e Auerswald et al. (1999). Os julgadores perceberam a diminuição progressiva da firmeza da polpa dos frutos e ratificam Suslow e Cantwell (2003), que afirmaram que o tomate deve ser firme ao tato e não deve se deformar facilmente.

A suculência apresentou leve declínio do estádio vermelho $(4,7$ e 3,6$)$ para o vermelho maduro $(4,3$ e 3,4$)$ nos tomates convencionais e orgânicos, respectivamente, sugerindo maturidade fisiológica completa e ponto ótimo para consumo. $\mathrm{O}$ resultado é compatível com Cliff et al. (2009) quando realizaram análise sensorial de tomates em estádios de maturação vermelho e vermelho maduro.

Os julgadores atribuíram o aspecto liso, considerado ideal à polpa do tomate orgânico, enquanto que a do convencional foi descrita como aspecto de esponja. Semelhante ao comportamento descrito por Auerswald et al. (1999), a espessura da polpa apresentou redução à medida que a coloração dos frutos mudava de vermelho para vermelho maduro.

A firmeza ao toque, firmeza ao corte e resistência ao corte refletiram a queda da textura oral com a evolução da maturação do fruto, confirmando Auerswald et al. (1999). No tomate convencional, apesar da maior espessura da polpa, esse atributo não interferiu na textura oral, talvez, em face da maior suculência da amostra. O amolecimento ou perda de firmeza da polpa resulta da solubilização das substâncias pécticas da parede celular pela ação da Pectinametilesterase (PME) e Poligalacturonase (PG), cujas atividades estão aumentadas no início do amadurecimento e na senescência e sobretudo a PG que registra o seu pico no estádio vermelho maduro (VILAS BOAS et al., 2000; FACHIN, 2003). O tomate convencional apresentou inferior firmeza ao corte, resistência ao corte e textura oral, contrariando o esperado, já que em mutante rin, como a cv. Raísa, a enzima PG apresenta traços de atividade (FACHIN, 2003), de modo a não exercer grandes modificações nos atributos de resistência do fruto; enquanto que no tomate orgânico, a cv. Santa Clara, que sugere uma atividade da PG normal, ocorreu uma maior firmeza nos estádios vermelho e vermelho maduro. Esses resultados podem ser justificados, pois tomates expostos a temperaturas elevadas têm seu metabolismo ativado com elevação da taxa de respiração e aumento da atividade das enzimas hidrolíticas PME e PG cuja atuação reduz a firmeza dos frutos (VILAS BOAS et al., 2000). Também a firmeza dos frutos está relacionada à nutrição da planta, disponibilidade de água no solo, estádio de maturação e características genéticas do fruto. Essa última determina a resistência da epiderme, textura do pericarpo, tecido da placenta e da estrutura interna do fruto, que, por sua vez, depende da relação entre o volume do pericarpo e o volume do material locular (WIEN, 1997; SUSLOW; CANTWELL, 2003).

A perda de aroma e sabor no tomate orgânico pode ser consequência do maior tempo de vida de prateleira em relação ao convencional, que atingiu o estádio passado em 14 dias, como também o intervalo de sete dias de demora para o tomate orgânico transpor o estádio vermelho maduro para passado (Tabela 1). Nessa fase ocorreu a perda de compostos voláteis responsáveis pelo flavor (sabor), gosto, doçura e acidez de tomates, os quais estão relacionados com o teor de açúcares, ácidos e compostos voláteis (AZODANLOU et al., 2003). Os valores do aroma e sabor são compatíveis com os registrados para açúcares solúveis, açúcares redutores, acidez titulável e ácido cítrico que estão diretamente relacionados com o aroma, sabor, perda do flavor, sabor estranho, doçura e sabor remanescente (AUERSWALD et al., 1999). Borguini (2002) encontrou maior valor no aroma e sabor para cv. Débora e Carmen.

Os julgadores perceberam o aumento do sabor estranho $(2,4$ e 2,9$)$ e sabor remanescente $(3,2$ e 3,4$)$ do tomate convencional com a evolução do estádio de maturação do fruto. Resultado contrário, que variou de 2,5 e 2,3 para sabor estranho e de 3,0 e 2,7 para sabor remanescente, foi verificado na amostra cultivada pelo sistema orgânico.

Houve predomínio da doçura sobre a acidez em todos os estádios de maturação, em ambos os sistemas de cultivos, com tendência do tomate convencional a apresentar frutos mais doces e mais ácidos que são atributos importantes para definir a qualidade. 
Ferreira et al.

Tabela 3. Análise microbiológica do tomate de mesa cultivado nos sistemas convencional e orgânico em diferentes estádios de maturação.

\begin{tabular}{ccccc}
\hline Amostra & Salmonella spp. (Presença em 25 g) & Coliformes totais (UFC.g ${ }^{-1}$ ) & Coliformes fecais (UFC.g ${ }^{-1}$ ) & Bolores e leveduras (UFC.g $^{-1}$ ) \\
\hline CVE & Ausente & 15 & $\mathrm{Nd}$ & $3,27 \times 10^{4}$ \\
CP & $\mathrm{Na}$ & $\mathrm{Na}$ & $\mathrm{Na}$ & $6,33 \times 10^{4}$ \\
CR & $\mathrm{Na}$ & $\mathrm{Na}$ & $\mathrm{Na}$ & $4,75 \times 10^{4}$ \\
CV & $\mathrm{Na}$ & $\mathrm{Na}$ & $\mathrm{Na}$ & $2,15 \times 10^{3}$ \\
CVM & $\mathrm{Na}$ & $\mathrm{Na}$ & $\mathrm{Na}$ & $5,66 \times 10^{3}$ \\
OVE & $\mathrm{Nusente}$ & $\mathrm{Na}$ & $\mathrm{Nd}$ & $1,11 \times 10^{4}$ \\
OP & $\mathrm{Na}$ & $\mathrm{Na}$ & $\mathrm{Na}$ & $2,9 \times 10^{4}$ \\
OR & $\mathrm{Na}$ & $\mathrm{Na}$ & $\mathrm{Na}$ & $3,09 \times 10^{4}$ \\
OV & $\mathrm{Na}$ & $\mathrm{Na}$ & $\mathrm{Na}$ & $3,53 \times 10^{3}$ \\
OVM & $\mathrm{Na}$ & $\mathrm{Na}$ & $\mathrm{Na}$ & $9,13 \times 10^{4}$ \\
\hline
\end{tabular}

Sistema convencional: CVE - convencional verde maduro; CP - Convencional Pintado; CR - Convencional Rosado; CV - Convencional Vermelho; CVM - Convencional Vermelho Maduro; sistema orgânico: OVE - orgânico verde maduro; OP - Orgânico Pintado; OR - Orgânico Rosado; OV - Orgânico Vermelho; OVM - Orgânico Vermelho Maduro; Na - Não analisado; Nd - Não detectado.

Os valores registrados na qualidade global mostraram que a evolução da maturação interfere na preferência dos julgadores. Na amostra convencional foi percebido um leve declínio $(6,2$ a 6,1$)$ na qualidade, enquanto que na amostra orgânica houve pequeno aumento $(5,8$ e 5,9$)$ na passagem para o estádio vermelho maduro. Esses resultados mostraram tendência dos frutos no estádio vermelho maduro a apresentarem características sensoriais superiores às do tomate no estádio vermelho, levando a crer que o ideal é consumir o fruto quando ele atinge a coloração vermelha e se encontra com textura e firmeza ao toque adequadas, o que ocorre aproximadamente de 7 a 8 dias da colheita, quando armazenado em temperatura ambiente.

$\mathrm{Na}$ análise microbiológica e na contagem de bolores e leveduras do tomate convencional e orgânico que estão na Tabela 3, não foi detectada a presença de Samonella spp. em 25 gramas, coliformes fecais (UFC. ${ }^{-1}$ ) e coliformes totais $\left(\mathrm{UFC}^{\mathrm{g}} \mathrm{g}^{-1}\right.$ ). A exceção foi a amostra convencional no estádio verde maduro, em que foram detectados coliformes totais (UFC. $\mathrm{g}^{-1}$ ), ainda que bem abaixo de $10^{2}$, indicada para hortaliças (REIS et al., 2003). Contaminação de 55,88\% por Escherichia coli foi encontrada por Pacheco et al. (2002) e Silva e Gallo (2003), que encontraram $2,4 \times 10^{1}$ de coliformes totais em tomates.

A contagem de bolores e leveduras apresentou comportamento semelhante entre os dois sistemas de cultivo, porém em menor quantidade para o tomate orgânico. Embora não sejam especificados padrões para bolores e leveduras de tomate e/ou hortaliças na legislação (BRASIL, 2001), foi adotada a contagem de $<10^{4}$ para garantir a proteção à saúde do consumidor uma vez que contagem superior pode ser perigosa em razão da possível formação de micotoxinas.

Nos estádios rosado e vermelho, independente do sistema de cultivo, a contagem de bolores e leveduras diminuiu, porém se manteve na ordem de $10^{3}$. No entanto, a partir do estádio vermelho maduro do tomate orgânico, ocorreu um aumento $\left(9,13 \times 10^{4}\right)$ da contagem de bolores e leveduras, levando a crer que as condições ambientais favoreceram a multiplicação ou promoveram a maior contaminação do produto.

Esses resultados levam a crer que o tempo ideal de para consumo humano, quando o produto é armazenado em temperatura ambiente, é de 8 dias para tomate orgânico e 10 dias para o tomate convencional, uma vez que a contagem elevada de bolores e leveduras indica risco ao consumidor, em especial, se o produto não for devidamente higienizado.

\section{Conclusões}

A tempo de armazenamento em temperatura ambiente é de 13 dias para o tomate convencional e de 14 dias para o tomate orgânico. No entanto, o ideal é consumir quando atinge a coloração vermelha, maior firmeza ao toque, melhor textura melhor suculência e baixa contagem de bolores e leveduras que ocorre aproximadamente em 8 dias para o tomate orgânico e em 10 dias para o tomate convencional.

A relação ST/ATT nas cultivares indica uma excelente combinação de açúcar e ácido que se correlacionam com sabor suave.

$\mathrm{Na}$ análise sensorial, a amostra de tomate orgânico apresenta polpa lisa, melhor firmeza ao toque, firmeza e resistência ao corte, textura oral e menor sabor remanescente, sabor estranho e acidez. A amostra de tomate convencional apresenta polpa com aspecto de esponja, menor número de defeitos de superfície, melhor sabor e qualidade global.

A contagem de bolores e leveduras é mantida na $10^{3}$ eindica que tomates conservados em temperatura ambiente necessitam de uma higienização eficiente antes de serem consumidos.

\section{Agradecimentos}

Ao Programa PIBIC/UFPR pela concessão de bolsa e à Associação dos produtores agrícolas de Colombo - APAC que cedeu as amostras.

\section{Referências bibliográficas}

AGENCE FRANÇAISE DE SEGURITE SANITAIRE DES ALIMENTS - AFSSA. Evaluation nutritionnelle et sanitaire des alimentis issus de l'agriculture biologique. Juillet, 2003.

AMERICAN PUBLIC HEALTH ASSOCIATION - APHA. Compendium of methods for the microbiological examination of foods. 3. ed. Washington, DC: American Public Health Association, 1992.

ASSOCIATION of Official Analytical Chemists. Official methods of analysis of AOAC international. 17. ed. Gaythersburg: M. D., 2000.

AUERSWALD, H. et al. Sensory analysis and instrumental measurements of short-term stored tomatoes (Lycopersicon esculentum Mill.). Postharvest Biology and Technology, v. 15, p. 323-334, 1999. 
AZODANLOU, R. et al. Development of a model for quality assessment of tomatoes and apricots. Lebensm.-Wiss. u.-Technol, v. 36, p. 223-33, 2003.

BATU, A. Determination of acceptable firmness and colour values of tomatoes. Journal of Food Engineering, v. 61, p. 471-475, 2004.

BHOWMIK, S. R.; PAN, J. C. Shelf life of mature green tomatoes stored in controlled atmosphere and high humidity. Journal of Food Science, v. 57, n. 4, 1992.

BORGUINI, R. G. Avaliação do potencial antioxidante e algumas características do tomate (Lycopersicon esculentum) orgânico em comparação ao convencional. 2006. 178 f. Tese (Doutorado em Saúde Pública)-Faculdade de Saúde Pública, Universidade de São Paulo, São Paulo, 2006.

BORGUINI, R. G. Tomate (Lycopersicon esculentum Mill.) orgânico: o conteúdo nutricional e a opinião do consumidor. 2002. $110 \mathrm{f}$. Dissertação (Mestrado em Agronomia)-Escola Superior de Agricultura Luiz de Queiroz, Universidade de São Paulo, Piracicaba, 2002.

BORGUINI, R. G.; OETTERER, M.; SILVA, M. V. Qualidade nutricional de hortaliças orgânicas. Boletim da SBCTA, Campinas, v. 37. n. 1, p. 28-35, 2003.

BOURN, D.; PRESCOTT, J. A comparison of the nutritional value, sensory qualities, and food safety of organically and conventionally produced foods. Critical Reviews in Food Science \& Nutrition, v. 42, n. 1, p. 1-34, 2002.

BRACKMANN, A. et al. Armazenamento de tomate cultivar "Cronus" em função do estádio de maturação e da temperatura. Ciência Rural, v. 37, n. 5, p. 1295-1300, 2007.

BRASIL. Ministério da Saúde. Agência Nacional de Vigilância Sanitária. Resolução RDC no 12 , de 2 de janeiro de 2001. Aprova o Regulamento Técnico sobre Padrões microbiológicos para alimentos. Diário Oficial [da] República Federativa do Brasil, Brasília, DF, jan. 2001. Seção 1, p. 6.

CARIS-VEYRAT, C. et al. Influence of organic versus conventional agricultural practice on the antioxidant microconstituent content of tomatoes and derived purees; consequences on antioxidant plasma status in humans. Journal of Agricultural and Food Chemistry, v. 52, p. 6503-6509, 2006.

CHIUMARELLI, M.; FERREIRA, M. D. Qualidade pós-colheita de tomates "Débora" com utilização de diferentes coberturas comestíveis e temperaturas de armazenamento. Horticultura Brasileira, v. 24, p. 381-385, 2006.

CLIFF, M. et al. Effect of 1-methylcyclopropene on the sensory, visual, and analytical quality of greenhouse tomatoes. Postharvest Biology and Technology, v. 53, n. 1-2, p. 11-15, 2009.

FACHIN, D. Temperature and pressure inactivation of tomato pectinases: a kinetic study 2003. 133 p. Proefschrift (Doctoraats in de Toegepaste Biologische Wetenschappen door)-Katholieke Universiteit Leuven, 2003.

FERREIRA, M. D. et al. Avaliação física do tomate de mesa 'romana' durante manuseio na pós-colheita. Engenharia Agrícola, v. 26, n. 1, p. 321-327, 2006.

FERREIRA, M. D. et al. Qualidade do tomate de mesa em diferentes etapas, da fase de pós-colheita. Horticultura Brasileira, v. 26, n. 2, p. 231-235, 2008.

FERREIRA, S. M. R. Características de qualidade do tomate de mesa (Lycopersicon esculentum Mill.) cultivado nos sistemas convencional e orgânico comercializado na Região Metropolitana de Curitiba. 2004. 249 f. Tese (Doutorado em Tecnologia de Alimentos)-Universidade Federal do Paraná, Curitiba, 2004.

HOBSON, G. E.; DAVIES, J. N. The tomato. In: HULME, A. C. The biochemistry of fruits and their products. New York: Academic Press, 1971. p. 437-475.

INSTITUTO ADOLFO LUTZ. Métodos físico-químicos para análise de alimentos. Coordenadores Odair Zenebon, Neus Sadocco Pascuet e Paulo Tiglea. 4. ed. São Paulo: Instituto Adolfo Lutz, 2008. 1020 p. Primeira edição digital.

KADER, A. A. et al. Composition and flavor quality of fresh market as influenced by some postharvest handling procedures. Journal of the American Society for Horticultural Science, v. 103, n. 1, p. 6-11, 1978.

KLUGE, R. A.; MINAMI, K. Efeito de esters de sacarose no armazenamento de tomates Santa Clara. Scientia Agrícola, v. 54, n. 1-2, p. 39-44, 1997.

MARTÍNEZ-ROMERO, D. et al. Effect of ethylene concentration on quality parameters of fresh tomatoes stored using a carbon-heat hybrid ethylene scrubber. Postharvest Biology and Technology, v. 51, p. 206-211, 2009.

NELSON, N. A. A photometric adaptation of the Somogyi method for the determination of glucose. Journal of Biology Chemistry, v. 153 , p. $375-380,1944$.

PACHECO, M. A. S. R. et al. Condições higiênico-sanitárias de verduras e legumes comercializados no Ceagesp de Sorocaba - SP. Revista Higiene Alimentar, v. 16, n. 101, p. 50-55, 2002.

RÊGO, E. R.; FINGER, F. L.; CASALI, V. W. D. Qualidade de frutos de tomate da cv. Santa Clara, mutante de fruto amarelo e seus híbridos F1. Horticultura Brasileira, v. 17, n. 2, p. 106-109, 1999.

REIS, K. C. et al. Avaliação da qualidade microbiológica de mini-milho (Zea Mays) minimamente processado. Revista Higiene Alimentar, v. 17, n. 110, p. 66-68, 2003.

SANINO, A; CORTEZ, L. B.; MEDERO, B. T. Vida-de-prateleira do tomate (Lycopersicon esculentum), variedade "Débora", submetido a diferentes condições de resfriamento. In: WORKSHOP DE TOMATE PERSPECTIVAS E PESQUISAS, 2003, Campinas. $6 \mathrm{p}$

SILVA, M. C.; GALLO, C. R. Avaliação da qualidade microbiológica de alimentos com utilização de metodologias convencionais e do sistema simplate. Revista Higiene Alimentar, v. 17, n. 107, p. 75-85, 2003.

SUSLOW, T. V.; CANTWELL, M. Tomate: (Jitomate). Recomendaciones para mantener la calidad postcosecha. Davis: Department of Vegetable Crops; University of California, 2003. 5 p.

VILAS BOAS, E. V. B. et al. Modificações textuais de tomates heterozigotos no loco Alcobaça. Pesquisa Agropecuária Brasileira, v. 35, n. 7, p. 447-1453, 2000.

WIEN, H. C. The physiology of vegetable crops. 2. ed. New York: Labi Publishing, 1997. $662 \mathrm{p}$.

WILLS, R. B. H.; KU, V. V. V. Use of 1-MCP to extend the time to ripen of green to tomatoes and postharvest life of ripe tomatoes. Postharvest Biology and Technology, v. 26, p. 85-90, 2002.

ZAMBRANO, J.; MOYEJA, J.; PACHECO, L. Efecto del estado de madurez en la composición y calidad de frutos de tomate. Agronomia Tropical, v. 46, n. 1, p. 61-72, 1996. 